\title{
Problemas de Citação em Publicações de Psicologia ${ }^{1}$
}

\author{
Almir Del Prette \\ Zilda Aparecida Pereira Del Prette \\ Universidade Federal de São Carlos
}

\begin{abstract}
RESUMO
Tendo em vista a formação de pesquisadores para a divulgação do conhecimento científico na Psicologia, este texto relata e categoriza alguns problemas comuns de citações, encontrados em um conjunto restrito de dissertações, teses, artigos e livros publicados no período de 2004 a 2007 . Os problemas foram identificados por dois pesquisadores que concordaram quanto à denominação, definição e exemplificação de oito categorias produzidas na análise: desnecessárias, vitrines, equivocadas, figura-fundo, atemporais, pulverizadas, sobrepostas e mascaradas. Defende-se um maior rigor na redação do texto científico com relação às citações, como forma de melhorar a identificação e valorização dos estudos em que o texto se baseia e de evitar problemas relacionados à fidelidade das ideias dos autores referenciados.
\end{abstract}

Palavras-chave: metodologia científica; redação científica; citações; erros de citação.

\section{ABSTRACT \\ Quotations Problems in Psychology Publications}

Considering the need to prepare researchers to communicate scientific knowledge in Psychology, this text reports and categorizes some common problems regarding citations found in a restrict pool of dissertations, thesis, published papers and books published between 2004 and 2007. Two researchers identified potential problems with complete agreement on the definition and the examples for each one of the eight categories produced by the analysis labeled as: unnecessary, showcase, mistaken, figure-ground, out-of-time, sprayed, superimposed and masked. The current report focuses on the need for more caution with the use of citations in scientific texts as a way to improve the identification and appreciation of the studies mentioned and to avoid inaccuracy regarding the original ideas of the quoted authors.

Keywords: scientific methodology; scientific writings; quotations; quotation mistakes.

Os manuais de metodologia abordam questões relacionadas às citações, em geral apresentando e discutindo os aspectos formais das normas, tanto em relação ao uso de informação própria, ou proveniente de outra fonte, incluída no corpo do trabalho, como à indicação da fonte na lista das referências. Poucas dessas publicações chamam a atenção para outras características das citações como, por exemplo, a de fidelidade ao pensamento do autor citado, evitando sobrepor ou confundir as ideias daquele que cita com as do que é citado.

Quanto a essas publicações, não se ignora a possibilidade de exceções e vale a pena fazer menção a uma delas. Trata-se da obra de Eco (1985) - Como se faz uma tese - cuja primeira edição no Brasil data de 1983, traduzida do original publicado em 1977, na
Itália. Além de cientista, Eco é um escritor de raro talento, que conseguiu fugir do estilo tradicional, geralmente árido, usado na abordagem de temas sobre metodologia científica. Ao contrário, Eco apresenta um texto bem humorado, com boa argumentação e recheado de muitos exemplos. Esse livro, apenas aparentemente semelhante à maioria das publicações sobre metodologia, aborda alguns problemas de citações com concisão, objetividade e parcimônia, indo além de um propósito meramente normativo.

O objetivo do presente texto também não é descrever ou relembrar normas, nem mesmo referenciar autores como Eco, ainda que se possa recomendá-los com insistência. Nesse sentido, existem vários títulos disponíveis, como Baptista e Campos (2007), Deslandes (2007), Marques e Madarin-de-Lacerda (1995), Minayo 
(1993), Seidl de Moura, Ferreira e Paine (1998) e outros, que podem contribuir tanto para o emprego correto de normas de citação, como para a elaboração de um adequado delineamento de pesquisa e demais quesitos relacionados. No entanto, as várias formas de citações, observadas atualmente nos trabalhos científicos, sejam dissertações, teses ou outros tipos de monografias, têm evidenciado um padrão preocupante que parece disseminado e resistente à mudança. Lamentavelmente, algumas vezes isso pode ser observado até mesmo em artigos e livros, sugerindo que há um estilo que pode se tornar tão habitual que aumenta o risco dessas falhas passarem despercebidas.

Esse padrão de fazer citações apresenta pelo menos três tipos de falhas: (a) exposição de ideia, parafraseada ou revestida com outros termos, sem a devida atribuição ao autor da mesma, podendo induzir o leitor a atribuir a autoria ao escritor do texto; (b) apresentação de ideias já há muito assimiladas pela cultura, ou seja, que já se tornaram lugares-comuns, com atribuição de autoria a alguém que simplesmente as repetiu; (c) relação excessiva, meramente descritiva, de estudos arrolados em sequência, à guisa de "elaboração teórica" do projeto, relatório ou artigo, mas sem os devidos e necessários nexos e reflexões que os justificam. Essa maneira "de introduzir o tema" faz com que o escritor permaneça oculto e pode ser interpretada como um subterfúgio porque, nesse processo, ele se desobriga da análise, realizando apenas o trabalho de transcritor de descobertas e ideias alheias.

O propósito deste ensaio é apresentar e analisar alguns dos problemas usuais de citações que, na maioria das vezes, aparentemente podem não infringir o uso formal das normas, conforme prescrito nos manuais, mas comprometem a fidelidade às ideias dos autores citados, prejudicando a originalidade do texto. Tais problemas foram constatados a partir da experiência dos autores deste ensaio, principalmente em atividades acadêmicas como avaliação de projetos de pesquisa, condução de disciplinas que focalizam a análise de projetos de pesquisa, docência em Programa de Pós-Graduação, participação em bancas de qualificação e defesa de mestrado e doutorado e, ainda, na orientação de alunos. Concomitantemente, examinando trabalhos publicados (artigos e livros), foram verificadas falhas semelhantes de citações.

Este ensaio não se baseia em uma amostra da literatura de Psicologia no país, mas em um conjunto de textos e publicações dessa área, que permitem e justificam tal reflexão, uma vez que essas falhas podem se tornar mais generalizadas. Por outro lado, ensaios dessa natureza poderiam incentivar estudos sistemáticos, por exemplo, em áreas diferentes da deste trabalho, ou relativas a períodos diferentes do que está sendo aqui referido.

\section{Problemas comuns de citações}

A análise aqui apresentada baseou-se na identificação de problemas recorrentes relacionados às citações, anotados nos últimos anos e aqui categorizados, definidos e exemplificados. Os exemplos foram, em grande parte, retirados de projetos, relatórios de pesquisa (monografias, dissertações etc.), artigos e livros, sendo ligeiramente alterados para resguardar o anonimato dos escritores. Em algumas categorias, além da exposição do problema, considerou-se importante apresentar alguns comentários, indicando forma alternativa de citação e/ou explicitando o tipo de erro cometido.

As categorias, apresentadas a seguir supõem uma ordem de menor para maior gravidade. Aquele que faz a citação, cujo texto é objeto desta análise, está sendo designado por escritor.

\section{- Citações desnecessárias}

São consideradas desnecessárias as citações referentes a ideias com pouco ou nenhum peso argumentativo no texto e/ou que já se tornaram de domínio público. No primeiro caso, pode-se exemplificar: "Webster-Stratton (1997) afirma que os problemas de comportamento podem aparecer tanto na infância quanto na adolescência". Para o segundo caso: "Aristóteles (apud Marías, 1973) afirma que o homem é um animal social" ou "Skinner (1953) efetuou experimentos com ratos para estudar o condicionamento operante...”. Essas citações não acrescentam informação significativa ao desenvolvimento da ideia e favorecem uma avaliação negativa do texto do escritor, pois parecem subestimar o conhecimento do leitor sobre assuntos de domínio geral.

\section{- Citações vitrines}

São citações meramente descritivas de autores e assuntos, arroladas ao longo do texto, mas carecendo dos nexos que deveriam ser construídos pelo escritor. A impressão que causa ao leitor é de uma vitrine de autores, sem que o escritor do texto explicite suas próprias ideias, ou raramente o faça. Essa forma de exposição de ideias e citações segue direção oposta àquela preconizada por Cozby (2003), de que o escritor precisa ter uma posição crítica sobre a literatura analisada. Um exemplo de "vitrine" de autores ocorre no trecho a seguir: 
Alguns estudos (Feitosa, 2003; Molina, 2003; Pastori, 2000) chamam a atenção para certo padrão de interação que ocorre entre o professor e o aluno em sala de aula ... Outras pesquisas (Hildebrand, 2000; Vila, 2005) apontam na mesma direção dos autores já citados (...). Romer (1995) chama atenção para os déficits em habilidades sociais de crianças...

\section{- Citações equivocadas}

São aquelas que atribuem, a um autor, termos, conceitos e dados que não foram produzidos por ele. Frequentemente tal autor aparece, indevidamente, junto a outros que de fato poderiam ser citados. Esse tipo de citação sugere uma análise superficial da literatura por parte do escritor do texto. É o caso, por exemplo, da primeira citação no trecho que se segue, indevidamente referenciada por não tratar especificamente da temática do texto, ainda que os autores possam ter outros trabalhos voltados para isso:

(...) problemas comportamentais apresentados pelas crianças (...) podem afetar a uma variedade de resultados negativos na adolescência (....) Pesquisas mostram que, quando não corrigidos, estes problemas continuarão exercendo uma influência negativa na fase adulta (Ferreira \& Marturano, 2005; Loeber, 1991; Severson \& Walker, 2002) (grifo dos autores).

\section{- Citações figura-fundo}

São aquelas em que um autor é referenciado como apoio ("fundo") quando na verdade o texto se fundamenta em seus conceitos e ideias e, portanto, deveria referenciá-lo com destaque ("figura"). Por exemplo, "A inteligência social é definida como... (Thorndike, 1938)". O autor citado aparece como apoio quando deveria, nesse caso, ser destacado, uma vez que o conceito de inteligência social foi por ele cunhado. $\mathrm{O}$ correto seria algo como: "Conforme Thorndike (1938), a inteligência social (...)"; ou "Thorndike (1938) define a inteligência social (...)."

Cozby (2003, p. 348) também chama a atenção para esse problema indicando que, quando o autor faz parte da narrativa, somente a data da publicação deve vir entre parênteses e, quando não faz parte, seu nome e data devem ser colocados entre parênteses. Os exemplos de citações, a primeira correta e segunda incorreta, utilizados por Cozby (2003, p. 348) são, respectivamente: "Markman (1991) verificou que a discordância conjugal (...) . Em um estudo (Markman, 1991), casais aprenderam a discutir (...)."

\section{- Citações atemporais}

São aquelas em que se atribui o mesmo pensamento a dois ou mais autores situados em momentos históricos bastante distanciados. É provável que essa forma seja usada com o objetivo de produzir maior impacto sobre a linha de argumentação pretendida. Por exemplo, "Vários autores (Sidman, 2003; Skinner, 1970), já há algum tempo enfatizam que vivemos em uma sociedade coercitiva".

Dois problemas podem ser identificados nesse tipo de citação. O primeiro é que fica a cargo do leitor identificar o critério utilizado para citar apenas esses dois autores, quando é sabido que outros pesquisadores também fizeram importantes contribuições para o conhecimento daquele assunto. Isso pode sugerir falha no levantamento de referências. Outro problema é a não contextualização, em termos do tempo e também da circunstância em que os conhecimentos foram gerados. Uma citação desse tipo só seria defensável se o objetivo do trabalho fosse o de comparar o pensamento especificamente desses dois autores em relação a esta ou outras questões que investigaram.

\section{- Citações pulverizadas}

São aquelas que aparecem em trechos compostos por várias categorias descritivas, sendo cada uma delas referenciada a autores diferentes quando todos esses autores, ou a maioria deles, também abordaram as demais categorias, ou pelo menos a maioria delas. Por exemplo:

Com relação aos estudos sobre práticas parentais, muitos aspectos são apresentados como: (a) deficiência de interações positivas dos pais com os filhos (Gonzales, 1997; Patterson, Reid, \& Dishion, 2002); (b) disciplina relaxada (Patterson, Reid, \& Dishion, 2002; Younger \& cols., 2000); (c) punição inconsistente (Loeber \& Hay, 1997; Magalhães, 1995; Jones, 2001); (d) negligência (Barber, 1996; Olaf, 2003).

Esse tipo de citação geralmente incorre em erro ao localizar os pesquisadores do tema apenas em alguns subtemas específicos. Outro problema em que incorre diz respeito ao nivelamento de informações, mascarando diferenças de métodos e contradições entre os dados obtidos.

\section{- Citações sobrepostas}

São aquelas em que uma mesma ideia (ou conceito, ou dado) é atribuída a dois autores, sendo que o mais recente baseou-se no anterior, deixando de explicitar o 
autor original da ideia. Por exemplo, "O termo habilidades sociais de trabalho se refere a um conjunto de classes de resposta que ocorre na interação de um indivíduo com o outro, no contexto de trabalho (Argyle, 1982; Drummond, 2005)". Uma consequência provável é a de, posteriormente, outros escritores passarem a citar apenas o segundo autor (porque este contribui para dar maior atualidade às suas referências), esquecendo-se do primeiro que foi, na verdade, o autor daquele conceito.

\section{- Citações mascaradas}

Esta categoria é definida iniciando-se pela contextualização do problema de citação aqui referido. Em uma frase, uma ideia é devidamente creditada a um autor, contudo, na continuidade do texto, novas frases ou períodos apresentam outras ideias do mesmo autor que não são a ele creditadas, supondo-se que a primeira citação seja suficiente. Pode-se exemplificar com a seguinte citação:

Gresham e Elliott (1990) conduziram muitas pesquisas de avaliação de habilidades sociais utilizando o Social Skills Rating System (SSRS). A análise fatorial desse instrumento produz fatores que agrupam diferentes tipos de habilidades sociais. $\mathrm{O}$ fator Cooperação reúne as habilidades de ajudar nas tarefas, manter o (...). O fator Asserção inclui as habilidades de (...) O fator Responsabilidade .... .

Uma variante dessa categoria é iniciar um parágrafo parafraseando as ideias de um autor que somente é referenciado muito adiante, em outra frase ou no final do parágrafo. Para esta variação, pode-se exemplificar: "O conceito de habilidades sociais remete às dimensões comportamental, situacional e cultural. A primeira refere-se (...) . A segunda indica que (...) A terceira mostra que as normas e regras vigentes em uma cultura podem (...) (Del Prette \& Del Prette, 2001)".

O equívoco do escritor é supor que a citação de uma ideia em uma frase dê crédito para todas as demais, sem se dar conta de que, se não recorrer a algum recurso de linguagem, cada citação vale somente para a frase em que a ideia é inserida. Para resolver isso, o escritor pode: (a) antecipar ao leitor que os termos ou conceitos apresentados na sequência do texto se referem a um mesmo autor; (b) começar novas frases com expressões que indicam isso, como, por exemplo, "Conforme esse autor (...); Resumindo as ideias desse autor (...); Na continuidade, o autor (...)".
As duas variantes dessa categoria são bastante frequentes. Em ambas, as ideias de um autor no trecho não referenciado passam a ser atribuídos ao escritor. Cabe lembrar ainda que as ideias e dados de pesquisas, transcritos em painéis, folhetos, apostilas, vídeos e outros materiais de divulgação restrita, sem o devido crédito a seus autores, também seria incluída nesta categoria.

\section{CONSIDERAÇÕES FINAIS}

A perspectiva adotada neste texto toma os problemas de citação como falhas ou equívocos, evitando qualquer julgamento de natureza ética a respeito do escritor. Contudo, a apropriação de ideias de outrem, mesmo que não intencional, pode ser considerada em uma dimensão ética e legal. Os problemas aqui apresentados, agrupados em apenas oito categorias, certamente não esgotam todas as possibilidades, mas representam equívocos muito frequentes nas citações. Existem alguns outros problemas recorrentes que, no entanto, podem ser facilmente superados desde que o escritor e seus pares na academia estejam bem atentos.

Ainda que não existam objeções legais, entende-se que a transcrição de tabelas, figuras e quadros deveria ocorrer com a devida autorização do editor (ou do autor, se ele for o editor), tendo-se o cuidado de citar e referenciar corretamente o autor e de explicitar no texto: "reprodução permitida pelo editor [ou autor]". Adicionalmente, pode-se lembrar que ideias ou dados não publicados, obtidos por meio de conversa, palestra, e-mail etc., também podem ser creditados aos seus respectivos autores. Nesse último caso, ainda que não represente uma obrigatoriedade prevista na lei sobre Direitos Autorais ${ }^{2}$, a citação é indicativa de elegância e mesmo de generosidade por parte do escritor.

Para superar essa forma de produção de textos, que aqui está sendo referida como um padrão ou estilo questionável, bem como os problemas mais comuns de citações, parece importante a capacitação do escritor em: (a) reconhecer a maneira correta de abstrair ideias e apresentar os respectivos créditos; (b) ler e reler seu texto, com objetivo de identificar os equívocos de citações cometidos na produção do mesmo e, se ainda restarem dúvidas, (c) solicitar a leitura de outras pessoas para uma correção final.

Considerando a realidade cultural brasileira, em que o universitário dedica pouco tempo à leitura, e menos ainda à construção de textos, parece impossível evitar equívocos de citações. Todavia, reduzir drasti- 
camente sua incidência é possível, desde que haja um esforço continuado para isso. Este trabalho representa uma tentativa de contribuir nessa direção e adicionalmente, de instigar novos estudos, por exemplo, no sentido de verificar se os tipos de problemas mais ou menos frequentes em determinada época, se mantêm ou se alteram em outras.

\section{REFERÊNCIAS}

Baptista, M. N., \& Campos, D. C. (2007). Metodologias de pesquisa em ciências: Análises quantitativa e qualitativa. Rio de Janeiro: LTC.

Brasil. (1998). Lei n. 9610. Altera, atualiza e consolida a legislação sobre direitos autorais e dá outras providências. Retirado em 24 de novembro de 2009, de http://www.planalto.gov.br/ccivil_03/Leis/L9610.htm

Cozby, P. C. (2003). Métodos de pesquisa em ciências do comportamento (P. I. C. Gomide \& E. Otta, Trads.). São Paulo: Atlas.
Deslandes, S. F. (2007). O projeto de pesquisa como exercício científico e artesanato intelectual. Em M. C. S. Minayo (Org.), Pesquisa social (pp. 31-60). Petrópolis, RJ: Vozes.

Eco, U. (1985). Como se faz uma tese (G. C. C. Souza, Trad.). São Paulo: Perspectiva.

Marques, E. A., \& Mandarim-de-Lacerda, C. A. (1995). Teses e dissertações: Estrutura e apresentação. Rio de Janeiro: UERJ.

Minayo, M. C. S. (1993). O desafio do conhecimento: Pesquisa qualitativa em saúde. São Paulo/Rio de Janeiro: Hucitec/Abrasco.

Seidl de Moura, M. L., Ferreira, M. C., \& Paine, P. A. (1998). Manual de elaboração de projetos de pesquisa. Rio de Janeiro: EDUERJ.

\section{Notas:}

1 Os autores agradecem a leitura e as sugestões da Profa. Dra. Edna Maria Marturano (Universidade de São Paulo, Ribeirão Preto) na versão inicial deste ensaio. Agradecem ainda aos dois pareceristas desta revista, pelas críticas e sugestões que muito contribuíram para o aperfeiçoamento da versão final.

2 A Lei 9.610, que altera, atualiza e consolida a legislação sobre direitos autorais e dá outras providências (Brasil, 1998), no Cap. IV, art. 46, incisos I e III, regulamenta a prática da "citação em livro, jornais, revistas ou qualquer outro meio de comunicação, de passagem de qualquer obra, para fins de estudo, crítica ou polêmica na medida justificada para o fim a atingir, indicando-se o nome do autor e a origem da obra". Parece que o espírito da lei é de não apenas preservar o direito de autoria, mas, igualmente, possibilitar ao leitor o acesso às fontes usadas em uma argumentação e, dessa forma, contribuir para a disseminação das ideias que constituem a base da construção de novos conhecimentos.

\section{Sobre os autores:}

\footnotetext{
Almir Del Prette: Professor Doutor Titular da Universidade Federal de São Carlos.

Zilda Aparecida Pereira Del Prette: Professora Doutora Titular da Universidade Federal de São Carlos.

Endereço para correspondência: Alameda das Ameixeiras, 60 - Parque Faber - 13516-358 São Carlos - SP. Endereço eletrônico: adprette@ufscar.br; zdprette@ufscar.br. Web-page: http://www.rihs.ufscar.br.
} 